\title{
A review on some investigations into sustainable machining techniques
}

\author{
Shrikant Gunjal ${ }^{l,}$, and Sudarshan Sanap ${ }^{l}$ \\ ${ }^{1}$ MIT ADT University, Loni Kalbhor, Pune, Maharashtra- 412 201, India.
}

\begin{abstract}
Machining plays a crucial role in process of economy through the way it contributes around $5 \%$ of the country's total economy. The method of machining has been changed through the last periods due to the competition within the market to urge more profit and High Speed Machining (HSM) plays the vital role to realize the equivalent. Hence, many researchers are working on reduction of the machining cost and consumption of energy. Hard to cut materials have long list of practical applications, which is the main reason to consider their research and development aspects. Thus, it's important to review the consequences of process parameters mainly like cutting speed, feed rate and depth of cut so as to determine the correlation with reference to key measuring parameters like tool life, surface roughness and tool wear. The authentication of this approach must be proved in future, using different experimental data as high speed machining leads to extreme machining temperature, sudden tool failure and subsequent adverse effects on overall machining performance in all the aspects. Sustainable machining techniques have the effective answer to avoid the adverse consequences of HSM. This paper emphasizes upon the review of application of various sustainable machining techniques like Minimum Quantity Lubrication (MQL), Cryogenic Technique, and Compressed Gas into the high-speed machining of hard to cut materials. Further, the appliance of vegetable based lubricants is highlighted for better comparison.
\end{abstract}

\section{Introduction}

It is well known fact that the manufacturing industry contributes significantly in terms of overall development worldwide. Most of the countries have observed the increase in industrial energy usage and production house contributes majorly in terms of $\mathrm{CO} 2$-emissions. With no surprise, modern society is striving for tailor made solutions across the product range. [1]. The thought of sustainability [2] is to overcome the issues that face from various segments, as it is important that many manufacturers adopt sustainable practices. Sustainable manufacturing consists of protection of environment, profit and social benefits of all these manufacturing areas. Manufacturing in alignment with sustainability and optimum machining aspects will serve the benefits of production house [3]. The idea of cleaner and sustainable production is related to creating services and products, utilizing procedures and frameworks that preserve the natural resources as well as the energy. Such model ought to be monetarily feasible, safe furthermore, energizing for workers and alluring for the consumers [4]. This research emphasize on the investigations into various parameters of machining and its effects on the sustainability.

\subsection{Sustainable machining}

Sustainable manufacturing requires the preservations of the energy as well as materials. It is related to ecological effect, energy utilization, operational security, labors wellbeing, management of waste, and cost of production. Sustainability is significant in the process of machining [5]. The sustainability of a production process is often achieved by integrating all the tiny factors so as to achieve sustainable machining. The important market demand has got to be considered in dependence to cost; quality that has got to consider while the delivery of the ultimate product. Along with major manufacturing/machining attributes; waste reduction is important area of consideration by the virtue of efficient utilization of resources $[6,7]$.

\section{Literature review}

The literature review focus on the authors contribution that have made the research and experiment to promote sustainable practices in order to consume less energy and enhance surface integrity. High speed machining is an

*Corresponding author: shrishrikantgunjal@gmail.com 
important manufacturing process and widely used for extrusion dies, automobile, medical and aeronautics industry applications. Considerable developments are happening in the area of machining of various hard and conductive materials under different machining conditions $[8,9]$.

Sustainable machining techniques viz. MQL, compressed gas, cryogenic etc. has shown environment friendly direction for better future in all the aspects. With wide research work; it has been observed that, sustainable machining techniques help to reduce cutting forces, temperature and overall machining cost along with improved surface finish, tool life and overall machining performance even in hard to cut materials (titanium alloy, nickel alloy, AISI series/ hardened steel materials) [10-12]. An exhaustive literature review in this regard showing the contributions of various researchers is a source of vision to look towards latest developments in the area. This is an attempt to categorize the various researches made by different researchers for the sake of deciding the direction or path of research for new researchers.

\subsection{High-speed machining and optimization}

Pawade et al. [13] have discussed the application of a novel approach called Jaya algorithm to optimize method parameters in turning of AISI S7 material at higher speed. The algorithm does not need any algorithm-specific control parameters. Tool nose radius, cutting speed, feed rate, and depth of cut are the important method parameters considered. Surface roughness and cutting force observed to be influenced by these parameters. L18 mixed Taguchi orthogonal array was used while the mathematical prediction models were developed for output using regression method.

Khedekar et al. [14] have observed that time affects majorly over thickness variation during the experimentation on nickel chrome in view of its wide range of application in plating. Shinde et al. [15] performed the experimental work to optimize the method parameters in the process of powder-mixed electrical discharge machining. They used fine abrasive particles of aluminium, silicon and silicon carbide powder during experimentation which was performed on laboratory developed set-up. Response surface methodology (RSM) was used to assess the process performance.

Kale et al. [16] found that performance of copper electrode is better over brass during machining of Inconel 718. Response surface analysis and D-optimal method is used for optimization of process parameters to find the minimum tool wear and maximum material removal.

\subsection{Cutting tool techniques based on cryogenic treatment}

Cryogenic is a potential machining technique of the cutting tool cooling and part, while performing an operation under consideration. Cryogenic machining basically refers to delivering the cryogenic fluid to the cutting surface during the machining which undergoes the extreme temperature during the operation and where there's change within the material characteristics. Coolant used is typically liquefied nitrogen at $-196^{\circ} \mathrm{C}$. Nitrogen is safe, non-combustible, and noncorrosive gas which can be stored [17, 18]. Rubio et al. [19] noted that, cold compressed air which is subsequent to cryogenic technique; improves the surface finish by the virtue of temperature reduction in the cutting zone. Pereira et al. [20] performed the experimental investigations into AISI 304 turning and found the improvement in tool life by $50 \%$ under cryogenic application. Also, they noted the possibility $30 \%$ increase in cutting speed compare to dry machining. Schoop et al. [21] implies the liquid nitrogen (LN2) at -195.8 temperatures during high speed machining of Ti-6Al-4V material. They noted the use of cryogenic cooling allow lowest tool wear $<10 \mu \mathrm{m}$ at higher cutting speed $(240 \mathrm{~m} / \mathrm{min}$.) and reduced surface roughness compared to flood machining. Pande and Patil [22] performed the experimentation to check the effect of method parameter followed by analysis of cutting speed and feed correlation with reference to surface finish. ANFIS model and statistical validation are found to be in agreement of experimentation.

Pusavec et al. [23] assessed the cryogenic machining for a nickel alloy; Inconel 718. They assessed the attributes of surface integrity for distinct combinations of lubrication conditions. The outcomes demonstrate that cryogenic machining procedures can be actualized to enhance the surface integrity quality in view of improved quality of final product. Pusavec et al. [24] also assessed the machining of Inconel 718 using RSM by developing a predictive model for MQL, cryogenic, dry and cryo-lubrication machining processes. ANOVA was used to validate the models. From the results it could be observed that the lubrication/cooling significantly affected the performance of machining. Pusavec et al. [25] further presented a machining observation of Ni-alloy (hightemperature) which indicated that the cost of tooling contributed majorly to the cost of overall production.

\subsection{Cutting tool techniques based on surface structuring}

Baisane et al. [26] found the higher surface roughness and lower material removal rate under the consideration of A12O3p. Taguchi method is used during the machining of composite materials. Bhople et al. [27] noted that cutting speed and depth of cut are major parameters affecting surface roughness and main cutting force respectively during machining of austempered ductile iron. Surface plot used to analyze the effects of feed rate, depth of cut and speed on surface finish, microhardness and cutting force. The validation of these models was done by ANOVA. Jadhav et al. [28] have performed drilling experimentation on Al6061/ Al2O3 aluminium metal matrix composite to study the effect on surface finish. Design of experiment was done by Taguchi method to know the effects of cutting speed, point angles of drill bits, feed rate and reinforcement 
percentage of $\mathrm{A} 12 \mathrm{O} 3 \mathrm{p}$ on cylindricity, mean force, torque and surface roughness.

Nizamuddin et al. [29] have compared the karanja oil with conventional cutting fluid during the orthogonal cutting of AISI 1045 steel and found better results with eco-friendly oil over the conventional fluid. Nilesh and Brahmankar [30] have experimented to incorporate the particles dimensions along with development of a replacement model for surface roughness. Experimental results are found to be in close agreement with predictions of this model. The nonlinear estimation results while machining of these composites projects the importance or properties like coefficient of thermal expansion, thermal diffusivity, melting temperature and heat of fusion. Pawade et al. [31] have noted the significant reduction in cutting force using honed plus chamfered cutting edge during machining of Inconel 718 super alloy at higher speed with PCBN cutting tool.

\subsection{Cutting tool techniques based on cooling and lubrication}

Wang et al. [32] performed the experimental evaluation during grinding under the application of MQL using different vegetable oil types. They performed the experiment on Ni- alloy (GH4169) and noted that use of vegetable oils namely castor, peanut, sunflower and soybean oil; help to achieve superior results in comparison of flood lubrication. Key ingredients of vegetable oils like ricinoleic and oleic acids which have low friction coefficient and high binding energy; helps in producing excellent lubrication properties they observed. On the equivalent line, Sunday et al. [33] concluded that use of MQL method using Bio- lubricant in various machining processes is an effective way to tackle environmental concerns, health issues and price related to the lubricant application during machining operation.

Sachin and Nilesh [34] have developed new cutting fluid during machining of M2 steel turning operation under MQL and compared it with traditional oil. Results show that surface roughness obtained under alove vera is better as compared to mineral oil. Further, reduced tool wear noted under alove vera application. Shrikant and Nilesh [35] have investigated that bio-lubricant canola oil performance is much closer to the synthetic oil results during the turning of hardened AISI 4340 material. Gunjal et. al. [36] found the similar kind of closer results with bio-lubricant coconut oil in comparison to synthetic oil during experimental investigation and noted less than micron variation in results of chip thickness study.

Pande and Patil [22] found that the application of vegetable oil under MQL had better lubrication in comparison to flood and mineral lubrication. They utilized liquid paraffin oil for assessing and comparing the lubrication properties of sunflower oil, castor, palm, rapeseed, maize, peanut and soybean as the MQL base oils. On the same line, Karkade and Nilesh [37] have performed turning experimentation on titanium alloy under cryogenic $\left(\mathrm{CO}_{2}\right)$ gas cooling. The comparative investigation was undertaken on surface integrity and process forces. Surface finish was noted to enhance up to $28 \%$ compared to dry cutting.

Thakur et al. [38] have analyzed machinability characteristics during Inconel 718 machining under dry and MQL conditions. Collected chips were analyzed using X-ray diffraction analysis. Results show that MQL application is far better than that of dry machining. Elshwain et al. [39] reviewed the coolant-lubricants based on gas. They concluded that in comparison to conventional cooling and dry cutting for nickel-alloys and machining titanium, most of the attributes of the gas based cutting fluids enabled a considerable improvement. Jozic et al. [40] have performed the Taguchi's design of experiment for optimizing the cutting environments and process parameters during the process of machining. It is seen that feed per tooth, cutting time and cutting condition applied a critical impact on different reactions. Therefore, the adequacy of this system was confirmed by an experimental test. The concerned study affirms that air cold system is often effectively applied when it's important to satisfy recently established attributes.

\subsection{Comparison table}

Table 1. Researchers contribution

\begin{tabular}{|c|c|c|c|}
\hline $\begin{array}{l}\text { Ref. } \\
\text { No. }\end{array}$ & Method & $\begin{array}{c}\text { Type of } \\
\text { Metals \& } \\
\text { Machining } \\
\text { Procedure }\end{array}$ & Evaluation metrics \\
\hline 4 & Taguchi & $\begin{array}{l}\text { AIMg3- } \\
\text { Milling }\end{array}$ & $\begin{array}{l}\text { Surface roughness, power } \\
\text { consumption }\end{array}$ \\
\hline 5 & $\begin{array}{l}\text { Taguchi, } \\
\text { ANOVA }\end{array}$ & $\begin{array}{l}\text { Magnesium } \\
\text { Alloy- } \\
\text { Turning }\end{array}$ & $\begin{array}{l}\text { Lubrication, surface } \\
\text { roughness and finish }\end{array}$ \\
\hline 24 & $\begin{array}{l}\text { ANOVA, } \\
\text { RSM }\end{array}$ & $\begin{array}{l}\text { Nickel } \\
\text { alloy, Dry } \\
\text { machining, } \\
\text { high speed } \\
\text { machining, } \\
\text { cryogenic }\end{array}$ & $\begin{array}{l}\text { Cooling lubrication and } \\
\text { tool life }\end{array}$ \\
\hline 25 & $\begin{array}{l}\text { Genetic } \\
\text { algorithm }\end{array}$ & $\begin{array}{l}\text { Nickel } \\
\text { alloy, Dry } \\
\text { machining, } \\
\text { cryogenic }\end{array}$ & $\begin{array}{l}\text { Energy consumption, } \\
\text { safety measures, and cost }\end{array}$ \\
\hline 38 & Taguchi & $\begin{array}{l}\text { Steel } \\
42 \mathrm{CrMo} 4- \\
\text { Milling }\end{array}$ & $\begin{array}{l}\text { Surface finish and cutting } \\
\text { force }\end{array}$ \\
\hline
\end{tabular}




\section{Conclusions}

The concerned review paper is an attempt to summarize the research effort to drive sustainable machining future for all the relevant machining operations. Though sustainable machining techniques has shown promising results to all the materials even at high speed; the subsequent challenge like complexity reduction and structuring for continuous improvement to orientate manufacturing towards excellence has to be evaluated effectively. This shows the sustainable machining as a potential approach for the modern manufacturing world which prompt for tool efficiency and low energy consumption for quality and overall machining performance.

\section{References}

1. Enomoto, T., \& Sugihara, T. Improvement of antiadhesive properties of cutting tool by nano/micro textures and its mechanism. Procedia Engineering, 19, 100-105 (2011).

2. Rahim, E. A., Ibrahim, M. R., Rahim, A. A., Aziz, S., \& Mohid, Z. Experimental investigation of minimum quantity lubrication (MQL) as a sustainable cooling technique. Procedia CIRP, 26, 351-354 (2015).

3. Gajrani, K. K., Suvin, P. S., Kailas, S. V., \&Sankar, M. R.. Hard machining performance of indigenously developed green cutting fluid using flood cooling and minimum quantity cutting fluid. Journal of Cleaner Production, 206, 108-123 (2019).

4. Fratila, D., and Caizar, C., "Application of Taguchi Method to Selection of Optimal Lubrication and Cutting Conditions in Face Milling of AlMg3," J. Cleaner Prod., 19(6-7), pp. 640-645 (2011).

5. Eker, B., Ekici, B., Kurt, M., and Bakır, B. "Sustainable Machining of the Magnesium Alloy Materials in the CNC Lathe Machine and Optimization of the Cutting Conditions," Mechanics, 20 (3), pp. 310-316 (2014).

6. Gajrani, K. K., \& Sankar, M. R. Sustainable Machining with Self-Lubricating Coated Mechanical Micro-Textured Cutting Tools. In Reference Module in Materials Science and Materials Engineering. Elsevier (2018).

7. Revuru, R. S., Posinasetti, N. R., VSN, V. R., \& Amrita, M. Application of cutting fluids in machining of titanium alloys - a review. The International Journal of Advanced Manufacturing Technology, 91 (5-8), 2477-2498 (2017).

8. Borlepwar, P. T. and Patil, D. N., Recent advances in electrical discharge machining process: a review. In IVth international conference on production and industrial engineering, CPIE (2016).

9. Bandapalli, C., Sutaria, B. M., \& Bhatt, V. D., High speed machining of Ti-Alloys-A critical review. In Proceedings of the 1st International and 16th
National Conference on Machines and Mechanisms (iNaCoMM2013) (pp. 18-20) (2013).

10. Sharma, A. K., Tiwari, A. K., \& Dixit, A. R. Effects of Minimum Quantity Lubrication (MQL) in machining processes using conventional and nanofluid based cutting fluids: A comprehensive review. Journal of Cleaner Production, 127, 1-18 (2016).

11. Park, K. H., Suhaimi, M. A., Yang, G. D., Lee, D. Y., Lee, S. W., \& Kwon, P. Milling of titanium alloy with cryogenic cooling and minimum quantity lubrication (MQL). International Journal of Precision Engineering and Manufacturing, 18 (1), 5 14 (2017).

12. Gill, S. S., Singh, J., Singh, H., \& Singh, R. Investigation on wear behaviour of cryogenically treated TiAlN coated tungsten carbide inserts in turning. International Journal of Machine Tools and Manufacture, 51 (1), 25-33 (2011).

13. R. S. Pawade, A. S. Awale, \& Brahmankar, P. K. Application of Jaya Algorithm in Optimization of High Speed Turning of AISI S7 Tool Steel (2016).

14. Khedekar, D., Gosavi, V., Gogte, C. \& Brahmankar, P., Optimization of Process Parameters of NickelChromium Electroplating for Thickness Variation using Genetic Algorithm. In International Conference on Communication and Signal Processing (ICCASP 2016). Atlantis Press (2016,).

15. Shinde, R., Patil, N., Raut, D., Pawade, R. \& Brahmaknakr, P., Experimental Investigations into Powder-Mixed Electrical Discharge Machining (PMEDM) of HCHCr D2 Die Steel. In International Conference on Communication and Signal Processing (ICCASP 2016). Atlantis Press (2016).

16. Kale, S., Khedekar, D., Brahmankar, P. \& Sadaiah, M., Some Investigations into the Electrical Discharge Machining of Inconel 718 Alloy using Copper and Brass Electrodes. In International Conference on Communication and Signal Processing (ICCASP 2016). Atlantis Press (2016).

17. Kalia, S. Cryogenic processing: a study of materials at low temperatures. Journal of Low Temperature Physics, 158 (5-6), 934-945 (2010).

18. Gill, S. S., \& Singh, H. Cryogenic treatment of materials: cutting tools and polymers. In Polymers at Cryogenic Temperatures (pp. 245-273). Springer, Berlin, Heidelberg (2013).

19. Rubio, E. M., Agustina, B., Marín, M., \& Bericua, A. Cooling systems based on cold compressed air: A review of the applications in machining processes. Procedia engineering, 132, 413-418 (2015).

20. Pereira, O., Rodríguez, A., Fernández-Abia, A. I., Barreiro, J., \& de Lacalle, L. L. Cryogenic and minimum quantity lubrication for an eco-efficiency turning of AISI 304. Journal of Cleaner Production, 139, 440-449 (2016).

21. Schoop, J., Sales, W. F., \& Jawahir, I. S. High speed cryogenic finish machining of Ti-6Al4V with 
polycrystalline diamond tools. Journal of Materials Processing Technology, 250, 1-8 (2017).

22. Pande, P. P. and Patil, N. G., Investigations into Machining of Inconel 718 by Using Adaptive Fuzzy Based Inference System. International Journal of Engineering Research, 3(5) (2014).

23. Pusavec, F., Hamdi, H., Kopac, J., \& Jawahir, I. S. Surface integrity in cryogenic machining of nickelbased alloy-Inconel 718. Journal of Materials Processing Technology, 211 (4), 773-783 (2011).

24. Pusavec, F., Deshpande, A., Yang, S., M'Saoubi, R., Kopac, J., Dillon, O. W., \& Jawahir, I. S., "Sustainable Machining of High Temperature Nickel Alloy-Inconel 718: Part 1-Predictive Performance Models," J. Cleaner Prod., 81, pp. 255-269 (2014).

25. Pusavec, F., Kramar, D., Krajnik, P., \& Kopac, J., "Transitioning to Sustainable Production-Part II: Evaluation of Sustainable Machining Technologies," J. Cleaner Prod., 18 (12), pp. 12111221 (2010).

26. Baisane, V., Patil, N., Lahane, S., Pawade, R. \& Brahmankar, P., December. Investigations into Wire Electro-discharge Machining of A6061/A12O3p Composites. In International Conference on Communication and Signal Processing (ICCASP 2016). Atlantis Press (2016).

27. Bhople, N., Patil, N. and Mastud, S., The Experimental Investigations into Dry Turning of Austempered Ductile Iron. Procedia Manufacturing, 20, pp.227-232 (2018).

28. Jadhav, S. S., Kakde, A. S., Patil, N. G. \& Sankpal, J. B., Effect of cutting parameters, point angle and reinforcement percentage on surface finish, in drilling of AL6061/A12O3p MMC. Procedia Manufacturing, 20, pp.2-11 (2018).

29. Nizamuddin, M., Agrawal, S. M. and Patil, N., The Effect of Karanja based Soluble Cutting Fluid on Chips Formation in Orthogonal Cutting Process of AISI 1045 Steel. Procedia Manufacturing, 20, pp.12-17 (2018).

30. Patil, N. G. \& Brahmankar, P. K., Semi-empirical modeling of surface roughness in wire electrodischarge machining of ceramic particulate reinforced Al matrix composites. Procedia CIRP, 42, pp.280-285 (2016).

31. Pawade, R. S., Joshi, S. S., Brahmankar, P. K. \& Rahman, M., An investigation of cutting forces and surface damage in high-speed turning of Inconel 718. Journal of Materials Processing Technology, 192, pp.139-146 (2007).

32. Wang, Y., Li, C., Zhang, Y., Yang, M., Li, B., Jia, D., \& Mao, C. Experimental evaluation of the lubrication properties of the wheel/workpiece interface in minimum quantity lubrication (MQL) grinding using different types of vegetable oils. Journal of cleaner production, 127, 487-499 (2016).
33. Lawal, S. A., Choudhury, I. A., \& Nukman, Y. A critical assessment of lubrication techniques in machining processes: a case for minimum quantity lubrication using vegetable oil-based lubricant. Journal of Cleaner Production, 41, 210-221 (2013).

34. Agrawal, S. M. and Patil, N. G., Experimental study of non-edible vegetable oil as a cutting fluid in machining of M2 Steel using MQL. Procedia Manufacturing, 20, pp.207-212 (2018).

35. Gunjal S. U. and Patil N. G., Experimental investigations into turning of hardened AISI 4340 steel using vegetable based cutting fluids under minimum quantity lubrication. Procedia Manufacturing, 20, pp.18-23 (2018).

36. S. U. Gunjal, S. B. Sanap \& N. G. Patil, Role of cutting fluids under minimum quantity lubrication: An experimental investigation of chip thickness, Materials Today: Proceedings, (2020).

37. Karkade, H. B. \& Patil, N. G., Comparative investigations into high speed machining of $\mathrm{AB}$ titanium alloy (Ti-6al-4v) under dry and compressed $\mathrm{Co} 2$ gas cooling environment. In AIP Conference Proceedings (Vol. 2018, No. 1, p. 020009). AIP Publishing (2018).

38. Thakur, D. G., Ramamoorthy, B. \& Vijayaraghavan, L., Influence of minimum quantity lubrication on the high speed turning of aerospace material superalloy Inconel 718. International Journal of Machining and Machinability of Materials, 13 (2-3), pp.203-214 (2013).

39. Elshwain, A. E. I., Redzuan, N., \&Yusof, N. M. Machinability of nickel and titanium alloys under of gas-based coolant-lubricants (CLS)-A review. International Journal of Research in Engineering and Technology, 2(11), 690-702 (2013).

40. Jozic', S., Bajic', D., \& Celent, L., “Application of Compressed Cold Air Cooling: Achieving Multiple Performance Characteristics in End Milling Process," J. Cleaner Prod., 100, pp. 325-332 (2015). 